\title{
Um poema de Hilda Hilst
}

\author{
Bernardo Nascimento de Amorim \\ Universidade Federal de Minas Gerais
}

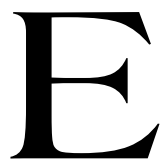

m 1992, Hilda Hilst publica Do desejo, uma coletânea de poemas que abarca a talvez mais densa fase de sua poesia. A três livros já lançados anteriormente, Sobre a tua grande face, de 1986, Amavisse, de 1989, e Alcoólicas, de 1990, acrescentam-se dois poemas inéditos, o primeiro deles com o mesmo nome da coletânea, e o segundo intitulado Da noite. Compostos ambos de dez partes e escritos na mesma época, estes últimos apresentam, em muitos sentidos, uma atmosfera temática e subjetiva semelhante. O questionamento existencial forma uma espécie de núcleo da experiência discursiva, em torno do qual se tecem as perguntas a respeito da passagem do tempo, do contato com o outro e do sentido das coisas, observadas sempre a partir da intermediação da linguagem.

Uma aproximação do poema de abertura do livro, que traria alguns dos traços centrais de toda a experiência poética de Hilst, pode vir a funcionar como uma introdução a este universo lírico e existencial, nos permitindo compreender muito do que se articula como o impulso original do fazer da poeta. Aqui, de fato, vêem-se os movimentos característicos desta poesia, marcada por uma conjugação entre a força diretriz do intelecto, a que se associa uma vontade de esclarecimento insubmissa aos limites do raciocínio, e a necessidade de expressão, ligada ao anseio de fazer da experiência afetiva a matéria prima da lírica. No âmbito deste artigo, uma análise do poema Do desejo pode ser efetivamente uma abertura à poética da autora, que não deixa nunca de tomar a investigação das vivências mais íntimas como condição de existência tanto do sujeito quanto da própria poesia. 


\section{2}

Do desejo, o poema, ${ }^{1}$ é precedido por uma epígrafe bastante significativa, em que o cerne interrogativo da poesia de Hilst, a sua tentativa de decifração do sentido das coisas, assim como a sua faceta dialógica, tornam-se logo evidentes:

Quem és? Perguntei ao desejo.

Respondeu: lava. Depois pó. Depois nada.

No trecho, a voz lírica se dirige diretamente ao desejo, lançando a este a pergunta sobre o que poderia vir a ser a essência de seu sentido, a substância da qual este elemento vital seria composto. A pergunta aparece em primeiro plano, para em seguida delimitar-se quem é que pergunta e a quem a interrogação se dirige. A resposta surge como se fosse o próprio desejo a falar, no entanto, intermediado pela voz de quem dirige o discurso. Na resposta, evidencia-se um percurso, que em imagens absolutamente concentradas, nos remete ao que há de mais cheio de energia e, em seguida, ao mais desprovido dela. A natureza do desejo, uma aspiração tornada objeto de reflexão, em um movimento que evidencia desde logo a tensão entre os processamentos do intelecto e as formas do afeto, mostra-se antes de tudo enquanto passagem, como uma substância efêmera, destinada a se extinguir na trajetória inexorável do tempo. A introdução a um poema que se propõe a dizer algo a respeito do desejo, com um título que nos remete ao ensaio filosófico, deixa evidente a atmosfera em que se inserirá todo o conjunto, assim como realça a vontade interrogativa da qual emana o próprio discurso. Na peça, percebese de fato que há um percurso em que o próprio desejo vai se transformando, a partir dos desdobramentos singulares da experiência e da reflexão do sujeito. Passemos à composição de número I:

Porque há desejo em mim, é tudo cintilância.

Antes, o cotidiano era um pensar alturas

\footnotetext{
${ }^{1}$ Do desejo, como aliás grande parte dos poemas de Hilda Hilst, é um conjunto formado por unidades de certo modo autônomas, poemas dispostos em seqüência numérica. No presente trabalho, será útil usarmos em alguns momentos o termo peça para nos referirmos ao conjunto como um todo, evitando repetições e ambigüidades.
} 
Buscando Aquele Outro decantado

Surdo à minha humana ladradura.

Visgo e suor, pois nunca se faziam.

Hoje, de carne e osso, laborioso, lascivo

Tomas-me o corpo. E que descanso me dás

Depois das lidas. Sonhei penhascos

Quando havia o jardim aqui ao lado.

Pensei subidas onde não havia rastros.

Extasiada, fodo contigo

Ao invés de ganir diante do Nada.

O poema, em que se faz uso sutil da exploração da sonoridade, e em que se destacam palavras diferencialmente grafadas com iniciais em maiúsculas, é composto basicamente a partir da oposição entre dois tempos, um passado e um presente, um antes e um hoje. Desde o segundo verso, o espaço do passado é marcado por um desejo de elevação, de encontro com uma esfera etérea em que o corpo é depreciado como algo em torno do que qualquer possibilidade de realização aparece interdita. O presente, pelo contrário, momento em que se vive uma experiência concreta de contato amoroso, remete positivamente a um espaço de luz, clareza e brilho, atributos tornados palpáveis justamente em decorrência da existência ou emanação corpórea do desejo, origem de uma iluminação que a tudo abarca. O movimento entre o antes e o hoje, cerne da construção do discurso, oscila em um percurso de idas e voltas. Do segundo ao quinto verso, fala-se da frustração de uma busca que nunca atinge a sua meta, da falta de correspondência entre o objeto de desejo e aquele que deseja, enquanto os dois versos seguintes desenham o espaço da aceitação e do elogio do corpo, em referência ao que caracteriza o humano, como o trabalho e a própria lascívia. Já no oitavo verso, os espaços se tocam, gerando uma certa continuidade, ainda que o passado seja mantido em seu lugar, apenas como lembrança de algo que não mais existe. O cruzamento, tecido na própria estrutura da frase, que projeta a sombra do passado na recente conquista do presente, permanece até o surgimento do penúltimo verso, a reforçar o lado mais instintivo das necessidades humanas, quando se associa a palavra fodo, baixo calão, que se impõe como um ponto de atrito em relação ao registro mais geral do poema, com o êxtase, momento também da cintilância, ligada ao desejo no primeiro verso. A oposição entre o corpo e o que poderia ser intuído como a alma, ainda que não se utilize esta nomenclatura, mas na medida em que se tem em mente uma tradicional oposição cristã, acaba por fazer do desejo, uma 
vez que se restringe ao contato físico, um atributo essencialmente necessário para a realização do homem na terra, em detrimento do contato com o alto. Ao encontrar-se na plenitude da manifestação do desejo corpóreo, a persona recusa enfaticamente a busca de tudo aquilo que poderia ser próprio a uma esfera do sagrado, identificado ao Nada, última palavra do poema, significativamente grafada com maiúscula, como no terceiro verso se grafa também Aquele Outro. O poema, primeiro momento da trajetória que se observará na peça, quando se tece a afirmação da positividade de um contato amoroso no plano da existência concreta, implica a recusa de algo que, apesar de sua grandiosidade, nenhuma serventia pareceria poder ter ao homem. O limite delineado entre o antes e o boje se configura como a manifestação de uma afirmação e de uma recusa tornadas conscientes, desdobradas a partir da determinação e da escolha entre um espaço da mais completa obscuridade, do vazio absoluto, e da luminosidade ou energia ardente.

Já o poema II, ${ }^{2}$ na medida em que promove uma maior aproximação da natureza da relação amorosa, apesar de continuar a afirmar a positividade do desejo, descortina uma experiência mais nuançada, que começa a ser problematizada. Abre-se espaço agora para a agonia, a tempestade. O que era antes apenas cintilância passa a ser constituído por uma substância ambígua e mesmo contraditória, sendo ao mesmo tempo cordura, sensatez e prudência, e crueldade, severidade. Inicia-se um aprofundamento que permitirá, em seguida, no poema III, o descortinar mais preciso de algumas das formas afetivas menos positivas com as quais a persona lírica experimenta a relação amorosa.

Na composição de número III, ${ }^{3}$ a voz poética utiliza-se largamente do recurso da adjetivação para qualificar-se como descomedida, árdua,

${ }^{2}$ Ver-te. Tocar-te. Que fulgor de máscaras. / Que desenhos e rictus na tua cara / Como os frisos veementes dos tapetes antigos. / Que sombrio te tornas se repito / O sinuoso caminho que persigo: um desejo / Sem dono, um adorar-te vívido mas livre. / E que escura me faço se abocanhas de mim / Palavras e resíduos. Me vêm fomes / Agonias de grandes espessuras, embaçadas luas / Facas, tempestade. Ver-te. Tocar-te. / Cordura. / Crueldade.

${ }^{3}$ Colada à tua boca a minha desordem. / O meu vasto querer. / O incompossivel se fazendo ordem. / Colada à tua boca, mas descomedida / Árdua / Construtor de ilusôes examino-te sôfrega / Como se fosses morrer colado à minha boca. I Como se fosse nascer / E tu fosses o dia magnânimo / Eu te sorvo extremada à luz do amanhecer. 
sôfrega, extremada. A amante continua a questionar, a partir da observação de si própria, no contato com uma alteridade feita interlocutor e amante, o que seria a própria natureza do desejo, elemento subjetivo, mas também abstrato, enquanto construto do intelecto. No quarto verso (Colada a tua boca, mas descomedida), a adversativa viria a apontar para uma certa precariedade da experiência amorosa, uma certa incapacidade de satisfação, que no primeiro poema, momento exclusivo de iluminação, ainda não existia. O percurso delineado na epígrafe, da lava ao nada, começa a avançar em uma direção que acaba por evidenciar tanto a necessidade do desejo enquanto impulso para uma possível forma de completude do ser humano, quanto a sua condição efêmera, marcada por uma transitoriedade que impediria, em última instância, a mais plena realização. O descomedimento, a vastidão do querer, próprios da persona lírica e atributos inerentes à substância do desejo, dificilmente poderiam encontrar uma satisfação absoluta, tal como pretenderia absorver (sorvo) o sujeito do poema. O descompasso entre o que se busca e o que se alcança, condição em que resta sempre a insatisfação, aponta para uma irremediável situação de falta, que em uma dimensão interpretativa mais ampla, mostra-se característica fundamental também do próprio ser humano.

Na seqüência, o poema IV nos apresenta algumas peculiaridades que podem revelar certos caracteres importantes do modo de composição de Hilst. Aqui, o movimento do intelecto mostra-se a fonte sobre a qual se assenta a fatura do texto, baseada nos processos típicos do raciocínio, que assumem a direção da estrutura do poema. Restringe-se ao âmbito do discurso, tornado único meio de vislumbre da superação das restrições do concreto, a possibilidade de transformação do real e da matéria:

Se eu disser que vi um pássaro

Sobre o teu sexo, deverias crer?

E se não for verdade, em nada mudará o Universo.

Se eu disser que o desejo é Eternidade

Porque o instante arde interminável

Deverias crer? E se não for verdade

Tantos o disseram que talvez possa ser.

No desejo nos vêm sofomanias, adornos

Impudência, pejo. E agora digo que há um pássaro

Voando sobre o Tejo. Por que não posso

Pontilhar de inocência e poesia

Ossos, sangue, carne, o agora

E tudo isso em nós que se fará disforme? 
Através do uso do condicional, associado ao verbo dizer, em uma estrutura dialógica, enumeram-se possibilidades que se desdobram em perguntas. Cria-se uma tensão entre a imagem poética e o que poderia ser uma verdade concreta, um jogo de oposições entre a esfera da fantasia, intermediada pela linguagem, e a dimensão do mundo real, existindo pretensamente sem mediação alguma. Por um lado, o poder do discurso é evidenciado, por outro, é ao mesmo tempo diminuído. No terceiro verso, diz-se que a palavra pouco importa, seja falsa ou verdadeira, porque se mostra absolutamente impotente diante da realidade imutável do universo. No sétimo verso, a palavra, por força do uso prolongado de uma coletividade (tantos o disseram), torna-se a própria verdade, mesmo que talvez, de fato, não seja. De um lado, coloca-se a linguagem e suas infinitas possibilidades, das quais a fantasia seria uma expressão poética. De outro, encontra-se a realidade enquanto tal, objeto que transcende a tentativa de compreensão. O espaço da criação, fundamento da atividade poética, cuja palavra poderia fundar uma existência de natureza extraordinária, intermediada pelas potências da linguagem, seria aberto justamente no intervalo que existe entre a busca da verdade e a impossibilidade de alcançá-la, tendo por base a simples observação do real. No jogo entre a fantasia e o que se apresenta como concreto, distingui-se a arbitrariedade ou o caráter convencional de tudo com o que se depara a percepção, o que implica uma opção lúcida da persona pela própria ilusão, um objeto resultante da imersão crítica e reflexiva do sujeito em suas experiências interrogativas e expressão dos movimentos que emanam de seu desejo.

O questionamento, orientado pelo desenvolvimento de uma lógica que tem em seu centro a hipótese e suas conseqüências para o raciocínio, domina o aspecto da construção que delineia todo o corpo do poema. O intelecto aqui não se opõe à sensibilidade, mas ambos atuam em conjunto como aliados contra as limitações da realidade. A partir do oitavo verso ressurge a presença afirmativa do desejo, enquanto motivo e forma que dá um aspecto mais atraente ao próprio mundo (adornos), e que, reunindo elementos dissonantes, como o cinismo (impudência) e o pudor (pejo), abre o espaço da invenção e da superação tanto do real quanto de uma lógica a ele imanente. No décimo verso inicia-se a pergunta que irá fechar o poema, quando se opõem novamente o concreto e o espaço da criação, deixando em evidência, ainda que matizada sob a sombra do questionamento, a possibilidade da poesia, enquanto universo de linguagem, acrescentar a tudo o que é efêmero uma centelha de eternidade. 
Também no poema $\mathrm{V}$, a centralidade dos procedimentos de linguagem, enquanto instrumentos de decifração do universo, continua evidente:

\author{
Existe a noite, e existe o breu. \\ Noite é o velado coração de Deus \\ Esse que por pudor não mais procuro. \\ Breu é quando tu te afastas ou dizes \\ Que viajas, e um sol de gelo \\ Petrifica-me a cara e desobriga-me \\ De fidelidade e de conjura. O desejo \\ Este da carne, a mim não me faz medo. \\ Assim como me veio, também não me avassala. \\ Sabes por quê? \\ Lutei com Aquele. \\ E dele também não fui lacaia.
}

A partir da definição do que seriam a noite o o breu, elementos que se oporiam ambos à luminosidade antes caracterizadora do desejo, desdobram-se os matizes da experiência afetiva do sujeito, tanto em relação à esfera do sagrado, percebida a partir do momento em que aparece a figura de Deus, quanto frente ao contato amoroso de dimensão terrena. No segundo verso, noite vem a ser o velado coração de Deus, este que não se deixa ver. No verso quatro, o breu é associado à ausência do amado. A experiência negativa começa a aproximar as duas esferas, apenas levemente diferenciadas, através de uma tentativa de questionamento que se volta para a compreensão da distinção entre o que estaria oculto e o que estaria ausente. Na seqüência, os dois espaços do desejo seriam mais bem definidos. No entanto, a diferenciação parece ser somente uma estratégia do discurso, que a elabora no sentido de revelar, por fim, a identificação. A partir do verso sete, por um lado, a persona afirma a sua segurança em relação a um desejo para o qual a carne é elemento fundamental, e por outro, coloca-se acima até mesmo das agruras de uma relação amorosa, identificada à luta, com a própria figura de Deus. Este, nomeado apenas como Aquele, ecoa a forma como aparece no poema I, Aquele Outro. A lembrança não vem por acaso, tornando-se significativa na medida em que se percebe como a dimensão positiva inicialmente associada ao desejo vai sendo problematizada. Apesar da persona recusar o papel de lacaia ou o sentimento do medo, o que fica evidente é antes a sua familiaridade com a escuridão. Em um movimento que conjuga a aproximação, na esfera da experiência afetiva, entre o espaço do amor 
como uma busca das alturas e a vivência das sutilezas de uma relação amorosa concreta, configura-se a evidência da negatividade e da profunda insatisfação a que remeteria, neste âmbito, a idéia do desejo.

Deixemos de lado o poema VI, para comentarmos algo bastante relevante a respeito do de número VII. ${ }^{4}$ Neste, outra vez se parte de uma tentativa de identificação do que sejam dois elementos distintos, embora muito próximos, agora, o amor e o desejo. O primeiro é identificado a um querer doloroso e de fastio. O segundo é qualificado como licencioso, indigno, e associado a um extraordinário turbilhão, àquilo que, escapando ao âmbito do ordinário, excita de modo violento. O discurso, dirigido a uma segunda pessoa, o amante que assume novamente a posição de interlocutor, concentra-se na tentativa de elucidação do que seria o desejo, o objeto privilegiado da interrogação, o que motiva uma tentativa de definição. Os procedimentos do poema, ultrapassando os limites da linguagem direta, aliam o impulso do raciocínio em busca do sentido das coisas e das experiências subjetivas, a uma transubstanciação que só a linguagem expandida através da analogia pode permitir. Do quinto ao oitavo verso, uma seqüência de imagens faz valer a potência da metáfora como um instrumento do qual faz uso o sujeito ao enfrentar os questionamentos a que se propõe. A analogia assume a direção do discurso justamente onde a lógica parece mostrar-se ineficiente, trazendo à tona uma forma de convivência entre os atributos do intelecto e a transfiguração lírica. As imagens, ao trazer os elementos de um descaminho e dos açoites, vivificam os adjetivos listados anteriormente, ampliando uma certa dimensão católica punitiva a que se associa a idéia do desregramento. Na seqüência, os três últimos versos do poema, dirigindo o questionamento diretamente ao interlocutor, voltam a fazer referência às imagens associadas ao desejo, desdobrando-se no vitalismo da última frase, que torna a problematizar a questão da diferenciação entre os conceitos em jogo, trazidos para a esfera da experiência. O último verso, particularmente construído a partir da ligação de elementos vitais (viva, veias), implica a

\footnotetext{
${ }^{4}$ Lembra-te que há um querer doloroso / E de fastio a que chamam de amor. / E outro de tulipas e de espelhos / Licencioso, indigno, a que chamam desejo. / Há o caminhar um descaminho, um arrastar-se / Em direção aos ventos, aos açoites / E um único e extraordinário turbilhão. / Por que me queres sempre nos espelhos / Naquele descaminhar, no pó dos impossíveis / Se só me quero viva nas tuas veias?
} 
recusa das diferenciações tecidas anteriormente no poema, na medida em que a imagem, ordenada no discurso em oposição àquelas que caracterizariam o desejo, parece também não poder ser associada ao amor, tal como este aparece nos primeiros versos. O fecho do poema parece dizer que, diante de um sentimento de tal forma intenso, as definições ou a compartimentação se tornariam ineficientes, revelando o malogro do movimento de distinção que teria dado origem à composição. O pensamento e a própria vivência concreta tornam-se impotentes ou precários, diante de um desejo ao mesmo tempo ligado aos sentidos e deles abstraído. O objeto que ultrapassa a possibilidade de definição e de diferenciação acaba por ser representado em tamanha magnitude que se exclui tanto a observação palpável de sua natureza, quanto a realização concreta da experiência amorosa. Relacionada ao corpo do amante, em uma troca que implica a dependência para a sobrevivência, a configuração do desejo ecoa uma dimensão negativa, a que se associa a ampla e recorrente idéia de incompletude.

No poema VIII volta a assumir um papel fundamental a tentativa de definição do que seja o desejo, agora grafado com maiúsculas. A partir do sétimo verso, começam as predicações:

DESEJO é um Todo lustroso de carícias

Uma boca sem forma, um Caracol de Fogo.

DESEJO é uma palavra com a vivez do sangue

E outra com a ferocidade de Um só Amante.

DESEJO é Outro. Voragem que me habita.

Novamente, conjugam-se a expansão da metáfora e o movimento do pensamento que se debruça sobre um objeto de reflexão. As imagens se sucedem na tentativa de tocar, tornando sensível e inteligível, o significado e a essência de um conceito que é também uma experiência subjetiva. Surge mais uma vez a dimensão da luminosidade, ligada agora a um sentido, o tato (carícias). Delineia-se também tanto a intangibilidade do desejo quanto o seu aspecto de energia, que remete novamente à idéia de lava, já apontada na epígrafe. Em seguida, aborda-se o desejo enquanto palavra, demonstrando desde logo a sua ambivalência, a sua natureza multíplice. Por um lado, faz-se referência à ligação entre a própria palavra e um elemento absolutamente vital para a existência humana, o sangue, e por outro, aparece um aspecto animalesco do desejo (ferocidade), ligado à onipotência de Um só Amante. A impossibilidade de abarcar aquilo que 
se fez objeto de reflexão, o que insiste em fugir às tentativas de definição, por mais que se faça uso dos variados instrumentos da linguagem e da percepção, torna-se mais uma vez evidente. Por fim, a persona identifica o desejo àquilo que devora, como uma espécie de abismo, a voragem, que é trazida para o seu próprio interior, como algo a ela imanente.

Indo mais além, ainda no âmbito do poema VIII, mas pensando no conjunto do todo, a referência ao Outro, no último verso, nos remete a Aquele Outro, que vimos aparecer antes no desenvolvimento da peça. Aqui, as maiúsculas com que se grafa a palavra desejo parecem encontrar a sua justificação, certamente necessária para o uso de qualquer procedimento em toda grande poesia. Se já vínhamos percebendo uma problematização em relação à positividade enunciada no poema I, cada vez mais acentuada no decorrer da trajetória da peça, agora percebemos o começo de um deslocamento que irá realizar-se completamente apenas no fechamento do conjunto. A diferenciação entre um desejo escrito com minúsculas e outro grafado com maiúsculas nos faz perceber a associação do primeiro com a relação concreta entre os amantes, enquanto o segundo se associa a tudo o que diz respeito ao Outro, significativamente também grafado, na primeira letra, com maiúscula. O poema VIII vem a ser justamente o momento em que se mostra o caráter sublime de um desejo ligado ao âmbito da transcendência, da elevação ou ainda, em outros termos, da própria alma. As imagens que não se deixam tocar, fugidias analogias, confirmam o caráter sublime de algo que escapa a toda compreensão. ${ }^{5}$

Se no poema I, o desejo ligado a um plano físico era associado a um alto grau de positividade, agora a perspectiva parece ser definitivamente alterada, uma vez que se diminui a sua essência, no corpo mesmo da letra que lhe dá forma. O poema de número $\mathrm{IX}^{6}$ talvez elucide de algum modo

\footnotetext{
${ }^{5}$ Um conceito certamente carregado de nuances e variações, o sublime nos serve aqui para nos referirmos ao que implica sempre em uma contemplação elevada por sobre o reino dos sentidos, ao incomensurável e ao indefinível. ${ }^{6}$ E por que haverias de querer minha alma / Na tua cama? / Disse palavras líquidas, deleitosas, ásperas / Obscenas, porque era assim que gostávamos. I Mas não menti gozo prazer lascívia / Nem omiti que a alma está além, buscando / Aquele Outro. E te repito: por que haverias / De querer minha alma na tua cama? / Jubila-te da memória de coitos e de acertos. / Ou tentame de novo. Obriga-me.
} 
esta transformação fundamental, que acaba sendo um retorno da posição da persona àquele antes enfaticamente recusado no poema I. A separação entre o corpo e a alma é tecida de modo claro quando a persona diz: a alma está além, buscando / Aquele Outro. A pergunta que é repetida no poema (E por que haverias de querer a minha alma na tua cama?), aponta para o limite da relação amorosa, restringida ao espaço do corpo (gozo, prazer, lascívia, coitos), que embora por si só não implicasse alguma negatividade, parece agora já não mais carregar aquele conteúdo de energia irradiante que lhe era peculiar no início da peça. Ainda no final do poema IX, o último verso faz referência a um modo de sedução ao qual a persona seria sensível. No entanto, também o imperativo, obriga-me, aponta antes para aquilo que o Outro, em sua plenipotência, seria capaz de realizar, do que para uma prática própria a um amante fragilizado em uma relação concreta e limitada pelas circunstâncias da natureza humana. De fato, aquele a quem se faria a pergunta central do poema parece ter mesmo perdido completamente o poder de sedução. O desejo corpóreo parece agora já em vias de extinção.

Finalmente, a última parte da peça define a unidade da trajetória do todo e a sua direção. Iniciado com uma imagem, logo em seguida, em um processo de metalinguagem, desvendada enquanto produto exclusivo da fantasia poética, o poema $\mathrm{X}^{7}$ traz para o verso a pergunta e as queixas do amante. A profunda diferença entre a mulher-poeta e o homem, este que parece não poder compreender a natureza de quem vive absorta em questionamentos e em um fazer que escapa inteiramente ao ordinário (códigos, conluios), que de improviso lança versos ao ar, acaba por criar um instransponível abismo entre os dois. Entretanto, são os quatro últimos versos, constituintes de uma segunda estrofe da composição, e ainda mais particularmente os três últimos, que trazem o cerne da significação mais ampla do poema:

\footnotetext{
7 Transcrevemos apenas a primeira estrofe, já que a segunda vem no corpo do texto: Pulsas como se fossem de carne as borboletas / O que vem a ser isso? perguntas. / Digo que assim há de começar o meu poema. / Então te queixas que nunca estou contigo / Que de improviso lanço versos ao ar / Ou falo de pinheiros escoceses, aqueles / Que apetecia a Talleyrand cuidar. / Ou ainda quando grito ou desfaleço / Adivinhas sorrisos, códigos, conluios / Dizes que os devo ter nos meus avessos. (...)
} 
Pois pode ser.

Para pensar o Outro, eu deliro ou versejo.

Pensá-LO é gozo. Então não sabes? INCORPÓREO É O

DESEJO.

O objeto do pensamento aqui é temporariamente, ou apenas aparentemente, mudado. Não se trata mais diretamente de uma reflexão sobre o desejo, mas antes, de pensar o Outro. Os procedimentos da poesia são nomeados de modo bastante claro. O delírio, um tipo de lucidez que ultrapassa os limites da lógica, é incorporado como forma essencial da atividade poética, que existiria então entre o raciocínio do discurso e a expansão imagética. O gozo já não se encontra mais ligado ao corpo, assim como o desejo se torna substância essencialmente etérea. Aquele Outro, um dos epítetos com os quais se alude à figura de Deus, representante da dimensão das alturas a que se associa a alma, em oposição ao corpo, torna-se o próprio objeto do pensamento e, por extensão, o objeto da atividade poética, enfim, o objeto do desejo. O impulso da reflexão, com o que se identifica a interrogação, a vivência do fazer poético e o próprio desejo tornam-se uma e a mesma coisa, indefiníveis por sua própria natureza. A persona do poema não se furta a afirmar a intangibilidade do objeto de sua procura. Diante do que escapa a toda tentativa de nomeação, do que não se deixa apreender nem pela razão nem pela imagem, toda arma mostra-se necessariamente falha. A busca acaba por tornar-se um fim em si mesmo, movimento vital impulsionado pela necessidade de decifração dos mistérios que o universo comporta. O gozo, a realização do sujeito, não mais se encontra na cintilância do contato com um amante de carne e osso, mas na atividade do espírito dinamizado pelo gesto de se traçar o caminho, de se escrever o poema. Este, como produto do espírito, do intelecto ou do delírio, acaba por mostrar-se o fim último de uma existência insatisfeita com os limites do real, com o possível fracasso da experiência amorosa e com a efemeridade e as contingências do concreto. Se o percurso do desejo tende a ser aquele que aponta a epígrafe do poema, da lava ao Nada, não restaria outra coisa a não ser fazer deste Nada, deste espaço que não se toca, que não se deixa ver, que não se diz, o objeto e o fim do próprio desejo. 


\section{3}

Não é um mero acaso ter Hilda Hilst dado à coletânea publicada em 1992, que como dissemos reúne parte de suas mais intensas composições, o mesmo nome do poema aqui analisado. O desejo na poesia da autora se manifesta como um impulso fundamental, chegando a ser aquilo que possibilita o próprio movimento de conformação da identidade do sujeito. É a partir dos desdobramentos mais íntimos da aspiração, dos encontros e desencontros a que dá ensejo, dos questionamentos e fantasias, que se garante a afirmação de uma subjetividade, a integridade da persona em torno da qual giram e adquirem significado os poemas.

Do desejo, o poema, nos oferece certamente uma dimensão central da poética de Hilst, uma lírica em que as demandas subjetivas vão de encontro aos grandes mistérios da existência, aqueles que permanecem como enigmas diante de qualquer tentativa de decifração. Nesta poesia, na qual se mescla uma busca de ordem conceitual, acerca da natureza dos objetos, a experiência afetiva, concentrada sobretudo na procura por contato com uma alteridade, seja em um plano concreto, seja em uma dimensão metafísica, e a expansão transfiguradora da lírica, não há como deixar de sobressair sempre um fundo de incompletude. Ao cabo do movimento de interrogação, não restam quaisquer promessas apaziguadoras, mas antes o encontro dos limites a que está preza a própria condição humana. Diante deles, a poeta manifesta a insistente afirmação da necessidade de se continuar a procura, este exercício que Hilst faz questão de assumir como meta. 


\section{Referências Bibliográficas}

CANDIDO, Antonio. O estudo analítico do poema. São Paulo: FFLCH-USP, 1993. (Terceira leitura, 2). 103 p.

COElHO, Nelly Novaes. Da poesia. Cadernos de Literatura Brasileira. São Paulo: Instituto Moreira Salles, n. 8, p. 66-79, out. 1999.

HILST, Hilda. Do desejo. Campinas: Pontes, 1992. 112 p.

HILST, Hilda. Das sombras. Cadernos de Literatura Brasileira. São Paulo: Instituto Moreira Salles, n. 8, p. 25-41, out. 1999. Entrevista.

PÉCORA, Alcir. Nota do organizador. In: HILST, Hilda. Cantares. São Paulo: Globo, 2002. (Obras reunidas de Hilda Hilst). p. 7-10.

PÉCORA, Alcir. Nota do organizador. In: HILST, Hilda. Da morte. Odes minimas. São Paulo: Globo, 2003. (Obras reunidas de Hilda Hilst). p. 7-10.

PÉCORA, Alcir. Nota do organizador. In: HILST, Hilda. Júbilo, memória, noviciado da paixão. São Paulo: Globo, 2001. (Obras reunidas de Hilda Hilst). p. 11-13.

QUEIROZ, Vera. Hilda Hilst: três leituras. Florianópolis: Mulheres, 2000. 74p. RIBEIRO, Leo Gilson. [Apresentação]. In: HiLst, Hilda. Ficções. São Paulo: Quíron, 1977. (Coleção jogral, 6). p. VII-XII.

\section{Resumo}

O artigo traz uma análise do poema Do desejo, acompanhando o seu movimento e destacando alguns dos traços fundamentais da poética de Hilda Hilst.

\section{Abstract}

The article introduces an analysis of the poem Do desejo, following its movement and distinguishing some essential marks of Hilda Hilst's poetics. 